\title{
Detection of cow milk adulteration in yak milk by ELISA
}

\author{
Q. R. Ren, ${ }^{* 1}$ H. Zhang, ${ }^{* 1}$ H. Y. Guo, ${ }^{*}$ L. Jiang, ${ }^{*}$ M. Tian, ${ }^{*}$ and F. Z. Ren ${ }^{*}{ }^{2}$ \\ *Beijing Laboratory for Food Quality and Safety, and Key Laboratory of Functional Dairy, College of Food Science and Nutritional Engineering, \\ China Agricultural University, Beijing 100083, P. R. China \\ †Beijing Higher Institution Engineering Research Center of Animal Product, Beijing 100083, P. R. China
}

\begin{abstract}
In the current study, a simple, sensitive, and specific ELISA assay using a high-affinity anti-bovine $\beta$-casein monoclonal antibody was developed for the rapid detection of cow milk in adulterated yak milk. The developed ELISA was highly specific and could be applied to detect bovine $\beta$-casein $(10-8,000 \mu \mathrm{g} / \mathrm{mL})$ and cow milk (1:1,300 to $1: 2$ dilution) in yak milk. Cross-reactivity was $<1 \%$ when tested against yak milk. The linear range of adulterant concentration was 1 to $80 \%$ (vol/ vol) and the minimum detection limit was $1 \%$ (vol/vol) cow milk in yak milk. Different treatments, including heating, acidification, and rennet addition, did not interfere with the assay. Moreover, the results were highly reproducible (coefficient of variation $<10 \%$ ) and we detected no significant differences between known and estimated values. Therefore, this assay is appropriate for the routine analysis of yak milk adulterated with cow milk.
\end{abstract}

Key words: yak milk, adulteration, monoclonal antibody, indirect competitive ELISA

\section{INTRODUCTION}

Yak milk is an important income source for rural residents of Qinghai-Tibetan Plateau, China. As a result of its high levels of proteins, lactose, conjugated linoleic acids, and calcium, yak milk is considered to be a naturally concentrated milk (Sheng et al., 2008; Li et al., 2011; Livingstone et al., 2012). Yak milk and yak milk-derived products (e.g., yogurt and cheese) have become increasingly popular in recent years (Bai et al., 2011; Nikkhah, 2011). Yak is a species that lives in mountainous areas of Central Asia, at an altitude

Received March 12, 2014.

Accepted July 9, 2014.

${ }^{1}$ The first two authors contributed equally to this paper.

${ }^{2}$ Corresponding author: renfazheng@263.net of 2,500 to $5,500 \mathrm{~m}$ (Zi et al., 2008). Yak lactation is seasonal, thus, yak milk production is quite limited (Wiener et al., 2003). Therefore, for legal, consumer protection, and consumer confidence reasons, it is important to be able to rapidly detect the presence of cow milk in yak milk to ensure yak milk quality.

To date, several analytical approaches have been developed to detect the adulteration of milk of different species in dairy products (Moatsou and Anifantakis, 2003; Hurley et al., 2004b). Infrared spectroscopy was applied to detect the adulteration of goat or sheep milk with cow milk (Rodriguez-Otero et al., 1997; Nicolaou et al., 2010). High-performance liquid chromatography coupled with electrospray ionization mass spectrometry was used to detect cow milk in goat milk (Chen et al., 2004). Brescia et al. (2004) used a nuclear magnetic resonance method to differentiate buffalo and cow milk samples according to species. Lee et al. (2004) detected the adulteration of cow milk in goat milk by PAGE. Two-dimensional electrophoresis was applied to detect bovine milk in buffalo Mozzarella cheese (Chianese et al., 1990). Enzyme-linked immunosorbent assay is a rapid, sensitive, and specific method that is widely used in the food industry (Giovannacci et al., 2004). Adulterated goat, sheep, or buffalo milk and milk products have been successfully detected by ELISA (García et al., 1990; Rodríguez et al., 1991; Haza et al., 1997, 1999; Hurley et al., 2004a, 2006; Song et al., 2011). However, no studies have applied ELISA to the detection of yak milk adulterated with cow milk.

To differentiate among different milk species, it is important to select species-specific antigens. Compared with whey protein, casein has higher heat stability, and $\beta$-CN has the highest specific antigenicity among caseins (Anguita et al., 1996). Therefore, we selected bovine $\beta-\mathrm{CN}$ as the target antigen in this study. The objectives of this study were to produce a high-affinity monoclonal antibody ( $\mathbf{m A b} \mathbf{1} \mathbf{- 9 B})$, which is specific against bovine $\beta-\mathrm{CN}$, and to develop a rapid and sensitive indirect competitive ELISA for the detection of cow milk in yak milk. Furthermore, we assessed the effect of different treatments (heat, acidification, and rennet addition) on the performance of the ELISA. 


\section{MATERIALS AND METHODS}

\section{Reagents and Materials}

Bovine $\beta$-CN (purity $\geq 98 \%$ ), Freund's complete and incomplete adjuvant, hypoxanthine-thymidine, hypoxanthine-aminopterin-thymidine selective medium, 3,3',5,5'-tetramethyl benzidine (TMB) liquid substrate, and Tween-20 were purchased from Sigma Chemical Co. (St. Louis, MO). Polyethylene glycol (PEG) 4000 was obtained from Merck (Darmstadt, Germany), and Dulbecco's modified Eagle's medium (DMEM) culture medium was purchased from Invitrogen (Grand Island, NY). Peroxidase-conjugated Affinipure goat anti-mouse IgG $\left(\mathrm{H}^{+} \mathrm{L}\right)$ was obtained from ZSGB-BIO (Beijing, China), and 96-well ELISA and cell culture plates were purchased from Costar (Cambridge, MA). The SP 2/0 myeloma cells were produced in our laboratory. Rennet (Stamix 1150, 1,070 international milk-clotting units/g) was purchased from Chr. Hansen (Hørsholm, Denmark). All other reagents were of analytical pure grade (Beijing Chemical Works, Beijing, China).

Fresh yak milk was obtained from Wushaoling town of the Tianzhu grassland, on the Qinghai-Tibetan Plateau. Fresh cow milk was obtained from Beijing San Yuan Foods Co. Ltd. (Beijing, China). Before analyses, all raw milk samples were first stored at $4^{\circ} \mathrm{C}$ and then frozen at $-20^{\circ} \mathrm{C}$ within $1 \mathrm{~h}$. Before the experiments, milk samples were skimmed by centrifugation at 3,000 $\times g$ for 20 min at $4^{\circ} \mathrm{C}$ and filtered through glass wool to remove lipids.

\section{Immunization}

The antigen solution was prepared by resuspending bovine $\beta-\mathrm{CN}$ in PBS $(0.5 \mathrm{mg} / \mathrm{mL})$ and stored at $-20^{\circ} \mathrm{C}$. The antigen solution was emulsified with an equal volume of Freund's complete adjuvant and injected $(50 \mu \mathrm{L})$ both subcutaneously and intraperitoneally into female BALB/c mice (6-8 wk old). Booster injections with Freund's incomplete adjuvant were performed 3 times with the same dosage at 2 -wk intervals. Blood samples were obtained from the tail 7 to $10 \mathrm{~d}$ after each booster injection. Antiserum was obtained by centrifugation at $10,000 \times g$ for 3 min at $4^{\circ} \mathrm{C}$.

\section{Monitoring Antibody Titers by Indirect ELISA}

The collected antiserum was assayed by indirect ELISA for antibody titer: each ELISA well was coated with $100 \mu \mathrm{L}$ of bovine $\beta$-CN diluted in coating buffer $\left(15 \mathrm{~m} M \mathrm{Na}_{2} \mathrm{CO}_{3}\right.$ and $35 \mathrm{~m} M \mathrm{NaHCO}_{3}$, pH 9.6) at $37^{\circ} \mathrm{C}$ for $2 \mathrm{~h}$. Following the 2 -h incubation, the wells were washed 3 times with PBS plus $0.05 \%$ Tween 20
$(150 \mu \mathrm{L} /$ well; PBST) for 2 min on a plate shaker and coated with $100 \mu \mathrm{L}$ of $5 \%$ defatted milk for $1 \mathrm{~h}$ at $37^{\circ} \mathrm{C}$. Following 3 successive washes with PBST, $100 \mu \mathrm{L} /$ well of antiserum diluted in antibody diluents (PBST with $0.1 \%$ gelatin) was added to the wells and the plates incubated for $1 \mathrm{~h}$ at $37^{\circ} \mathrm{C}$. The plates were washed as described above. Following the addition of $100 \mu \mathrm{L}$ of peroxidase-conjugated Affinipure goat anti-mouse IgG diluted 1:5,000 in antibody diluent, the plates were incubated for $30 \mathrm{~min}$ at $37^{\circ} \mathrm{C}$ and washed with PBST. Then, TMB was added to each well $(100 \mu \mathrm{L} /$ well $)$ and the plates were incubated for $15 \mathrm{~min}$ at $37^{\circ} \mathrm{C}$. The reaction was stopped with $2 \mathrm{M} \mathrm{H}_{2} \mathrm{SO}_{4}(50 \mu \mathrm{L} /$ well $)$. Absorbance was measured by using a microplate reader (model 680, Bio-Rad, Hercules, CA) at $450 \mathrm{~nm}$.

\section{Production of the Monoclonal Antibody}

The mouse with the highest antibody immunization titer was injected intraperitoneally with $100 \mu \mathrm{L}$ of antigen solution without adjuvant $3 \mathrm{~d}$ before fusion. The spleen was removed for hybridoma production (Devi et al., 1999). After fusion, hybridoma cells were screened by indirect ELISA for the presence of antibodies against bovine $\beta$-CN. Positive hybridoma cells were also tested against casein extracted from yak milk. Then, hybridomas selected to produce specific antibody were subcloned by the limiting dilution method (Köhler and Milstein, 1975). Cells with the highest antibody titer and specificity were selected during each subcloning until a single positive hybridoma was obtained. Subcloning was repeated 5 times to obtain positive monoclonal antibody ( $\mathbf{m A b}$ )-producing cells. Monoclonal antibody 1-9B was produced using the mouse ascites method (Cho et al., 2005). Animals were killed by cervical dislocation under the anesthesia. All animal maintenance and experimental procedures were conducted in accordance with the principles and specific guidelines presented in Guidelines for the Care and Use of Agricultural Animals in Research and Teaching (FASS, 2010) and approved by the Animal Ethics Committee of China Agricultural University. The resulting antibodies were purified by ammonium sulfate precipitation (Walker, 1996).

\section{Detection of $\beta-C N$ and Cow Milk and Assessment of Cross-Reactivity}

Following optimization of the assay by checkerboard titration, $\mathrm{mAb} 1-9 \mathrm{~B}$ was used to detect $\beta-\mathrm{CN}$ and cow milk by indirect competitive ELISA.

The inhibitory concentration was calculated as follows: $\%$ inhibition $=\% \mathrm{~B} / \mathrm{B}_{0}$, where $\mathrm{B}$ and $\mathrm{B}_{0}$ are the 
absorbance in the presence and absence of the competitor, respectively. Fifty percent inhibition was the competitor concentration at which the absorbance was half of $\mathrm{B}_{0} ; 50 \%$ inhibition for each compound was determined based on its inhibition curve.

To assess the specificity of $\mathrm{mAb} 1-9 \mathrm{~B}$, its cross-reactivity (CR) with yak milk was evaluated by indirect competitive ELISA based on comparison of the halfmaximal $(50 \%)$ inhibitory concentrations of yak milk and cow milk. The CR was calculated as follows: CR $(\%)=$ (concentration of standard cow milk inhibiting $50 \%$ antibody binding)/(concentration of yak milk inhibiting $50 \%$ antibody binding $) \times 100$.

The indirect competitive ELISA was performed as follows. Plates were coated at $37^{\circ} \mathrm{C}$ for $2 \mathrm{~h}$ with 100 $\mu \mathrm{L} /$ well of bovine $\beta-\mathrm{CN}$ in coating buffer. The plates were then emptied, washed, and blocked with $100 \mu \mathrm{L} /$ well of coating buffer plus $5 \%$ dried nonfat milk powder for $1 \mathrm{~h}$ at $37^{\circ} \mathrm{C}$. After the plates were washed 3 times with PBST, bovine $\beta$-CN, cow milk, or yak milk, previously diluted in antibody diluents and mixed with an equal volume of ascites antibodies at $37^{\circ} \mathrm{C}$ for $1 \mathrm{~h}$, was added to the wells $(100 \mu \mathrm{L} /$ well $)$ and incubated at $37^{\circ} \mathrm{C}$ for $1 \mathrm{~h}$. The plates were then washed 3 times with PBST before being incubated with $100 \mu \mathrm{L} /$ well of peroxidase-conjugated Affinipure goat anti-mouse IgG diluted 1:5,000 in antibody diluent for $30 \mathrm{~min}$ at $37^{\circ} \mathrm{C}$. The plates were washed as described above and then incubated with $100 \mu \mathrm{L} /$ well of TMB for $15 \mathrm{~min}$ at $37^{\circ} \mathrm{C}$. The reaction was stopped with $50 \mu \mathrm{L} /$ well of $2 \mathrm{M}$ $\mathrm{H}_{2} \mathrm{SO}_{4}$ and the absorbance was measured at $450 \mathrm{~nm}$ on a microplate reader.

\section{Detection of Cow Milk in Yak Milk}

The adulteration standards were prepared in 3 independent batches in which the reference skimmed cow and yak milk samples were mixed at varying percentages: $1,5,10,20,40,60,80,90$, and $100 \%$ (vol/vol). The samples were detected in triplicate by the optimized indirect competitive ELISA as described above. The standard curves were validated by quantifying the adulteration in blind samples.

\section{Detection of Adulterated Milk Samples with Different Treatments}

Heat Treatment. Cow milk and adulterated yak milk (containing 1-100\% cow milk) were subjected to different heat treatments, including pasteurization $\left(65^{\circ} \mathrm{C} \times 10 \mathrm{~min}\right)$, heat treatment at $95^{\circ} \mathrm{C}$ for $10 \mathrm{~min}$, UHT treatment $\left(138^{\circ} \mathrm{C} \times 4 \mathrm{~s}\right)$, or spray drying (150 to $160^{\circ} \mathrm{C} \times 10-20 \mathrm{~s}$ ). Fresh (untreated) and heat-treated samples were analyzed in triplicate by indirect competitive ELISA.

Acidification Treatment. The adulteration standards were prepared as described above. Each adulterated yak milk sample (containing 1-100\% cow milk) was acidified to $\mathrm{pH} 6.3,5.8,5.0$, or 4.6 with $0.5 \mathrm{M}$ $\mathrm{HCl}$. Four different $\mathrm{pH}$ and raw milk samples were prepared and analyzed in triplicate by indirect competitive ELISA.

Rennet Treatment. The adulteration standards were prepared as described above. Rennet solution, which consisted of rennet and sterile water $(1: 40, \mathrm{wt} /$ wt), was added $(60 \mu \mathrm{L})$ to each adulterated yak milk sample $(30 \mathrm{~g})$, mixed in a vortex for $30 \mathrm{~s}$, and incubated in a water bath at $32^{\circ} \mathrm{C}$ for $1 \mathrm{~h}$. The coagulum formed was cut and rested for $5 \mathrm{~min}$. The expelled whey was centrifuged at 2,500 $\times g$ for $15 \mathrm{~min}$ at room temperature and decanted, and the remaining curd was obtained and readjusted with PBS to the natural concentration of milk (the concentration of casein was about $28 \mathrm{~g} / \mathrm{L}$ ) and homogenized in a mechanical blender (Haza et al., 1999). The samples were prepared in triplicate and then analyzed by indirect competitive ELISA. The coagulation test was run in triplicate. The coagulated samples were re-adjusted to the natural concentration of milk with the addition of PBS, homogenized in a mechanical blender (Haza et al., 1999), and analyzed by indirect competitive ELISA.

\section{RESULTS AND DISCUSSION}

\section{Optimization of ELISA}

Highly specific $\mathrm{mAb} 1-9 \mathrm{~B}$ against bovine $\beta-\mathrm{CN}$ was successfully produced by monoclonal antibody technology. An indirect competitive ELISA of high sensitivity and specificity was designed to detect the presence of cow milk in yak milk using mAb 1-9B. The optimum plate-coating concentration and primary antibody dilution were determined by checkerboard titration. As shown in Figure 1, absorbance remained high at a concentration of $1 / 128,000$, indicating high sensitivity of the monoclonal anti-bovine $\beta$-CN antibody. Based on the results, the optimum plate coating concentration was $5 \mu \mathrm{g} / \mathrm{mL}$ and the optimum primary antibody (mAb 1-9B) dilution was 1:2,000.

\section{Detection Limit of Bovine $\beta-C N$ and Cow Milk}

The ability of $\mathrm{mAb} 1-9 \mathrm{~B}$ to detect bovine $\beta-\mathrm{CN}$ was assessed by indirect competitive ELISA. The working concentration of bovine $\beta-\mathrm{CN}$ detection ranged from 10 to $8,000 \mu \mathrm{g} / \mathrm{mL}$ (Figure 2a). The minimum detection 


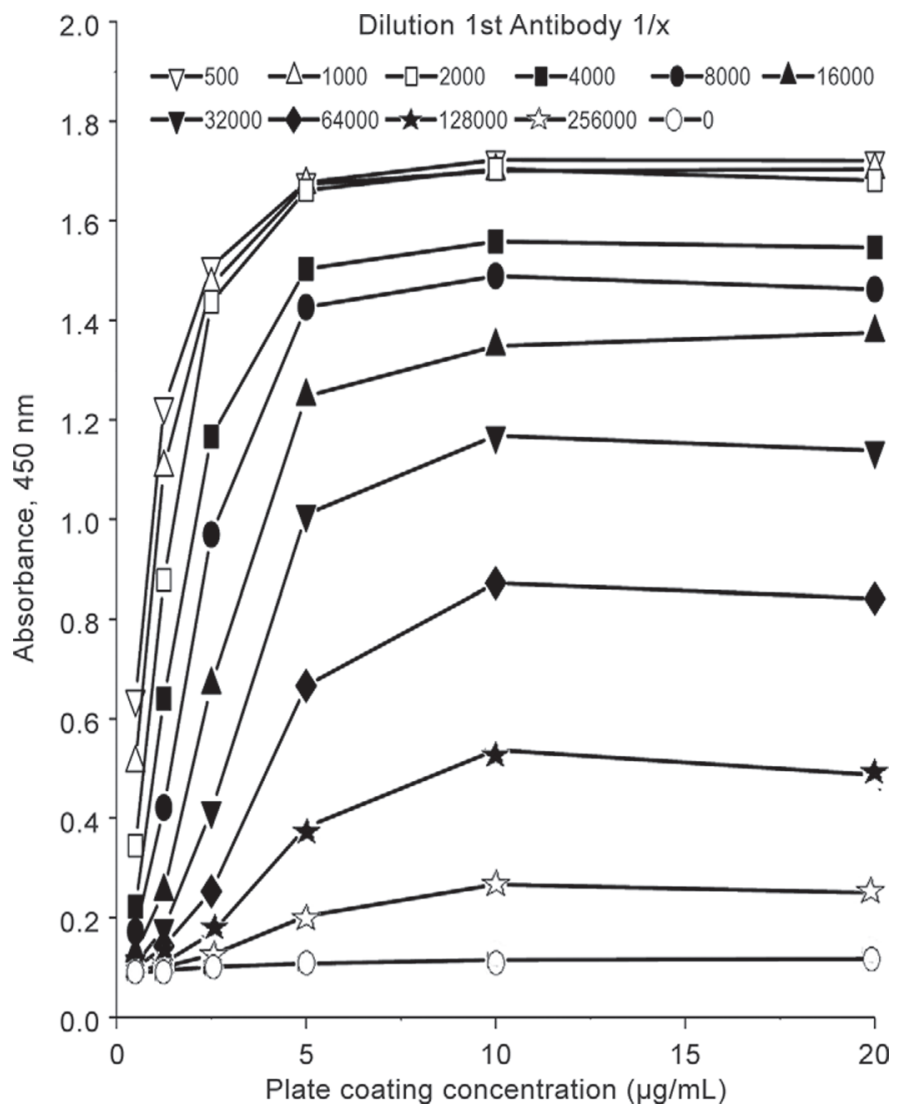

Figure 1. Indirect checkerboard ELISA to determine optimum plate-coating concentration and primary monoclonal antibody $(\mathrm{mAb}$ 1-9B) dilution. Different plate-coating concentrations and $\mathrm{mAb} 1-9 \mathrm{~B}$ dilutions were tested. Dilution of the second antibody (peroxidaseconjugated goat anti-mouse IgG) was 1:5,000.

limit and $50 \%$ inhibition for $\beta$-casein were 10 and 300 $\mu \mathrm{g} / \mathrm{mL}$, respectively. The linear correlation coefficient was -0.99 .

As shown in Figure 2b, cow milk at different dilutions was detected. The linear range was from 1:1,300 to 1:2 diluted cow milk. The minimum detection limit and $50 \%$ inhibition for cow milk were 1:1,300 and 1:50 dilution, respectively. The linear correlation coefficient was -0.99 . The content of $\beta$-CN is approximately $36.9 \%$ in cow milk proteins (Braga et al., 2006; De Marchi et al., 2010). The linear range of cow milk (i.e., 1:1,300 to $1: 2$ dilution) was equal to 9 to $6,000 \mu \mathrm{g} / \mathrm{mL} \beta-\mathrm{CN}$. This observation was similar to the detecting range of $\beta$-CN described above, suggesting that the detection of $\beta-\mathrm{CN}$ using mAb $1-9 \mathrm{~B}$ was not affected by other cow milk proteins.

\section{ELISA Specificity}

The $\mathrm{CR}$ of $\mathrm{mAb} 1-9 \mathrm{~B}$ with yak milk was determined by indirect competitive ELISA. As illustrated in Figure
3 , the results revealed that $1 / 50$ and $1 / 0.42$ dilutions of cow milk and yak milk resulted in 50\% inhibition, respectively. The $\mathrm{CR}$ of yak milk was $<1.0 \%$ against cow milk. According to Yin et al. (2010), our results indicate that $\mathrm{mAb} 1-9 \mathrm{~B}$ has relatively low $\mathrm{CR}$ toward yak milk, and our assay can be considered to be highly specific for bovine $\beta-\mathrm{CN}$. Therefore, mAb 1-9B can be used to detect the adulteration of yak milk with cow milk.

\section{Detection of Cow Milk in Yak Milk}

The inhibition curve of adulterated yak milk is shown in Figure 4. The linear range of detectable adulterant concentration was 1 to $80 \%$ ( $\mathrm{vol} / \mathrm{vol}$ ) with a linear correlation coefficient of -0.98 ; the minimum detection limit of the assay was $1 \%$ ( $\mathrm{vol} / \mathrm{vol})$. The assay was highly reproducible with intra-and interassay coefficients of variation $<10 \%$ (Supplementary Tables S1 and S2; http://dx.doi.org/10.3168/jds.2014-8127). The standard curve was applied in a single blind trial. Based on the trial, the presence of cow milk could be estimated in the range from 1 to $80 \%$; we detected no significant differences between known and estimated values $(P=0.18)$. The $\mathrm{mAb}$ AH4 anti-bovine $\beta$-CN was produced for the detection of cow milk in ewe and goat milks with a working range of 1 to $10 \%$ (Anguita et al., 1995). Song et al. (2011), who used modified polyclonal antibodies against bovine $\beta$-CN to detect the presence of bovine milk in Shaanxi goat milk, reported that the working range was 2 to $50 \%$. Compared with their findings, our monoclonal antibody had a wider working range and applicability for the detection of adulterated yak milk with cow milk. Furthermore, at present, the reference method can detect $1 \%$ cow milk in sheep milk (European Commission, 2001). Because adulteration of less than $1 \%$ would not be economically profitable, the method described here is adequate for quantitative testing. Therefore, this assay can be adequately applied in routine adulteration testing.

\section{Detection of Adulterated Milk Samples with Different Treatments}

Heat Treatment. Monoclonal antibody 1-9B was used to detect different heat-treated cow milk samples. The inhibition curves of pasteurized, UHT, and spraydried samples were similar to those of fresh (untreated) samples (Supplementary Figure S1; http://dx.doi. org/10.3168/jds.2014-8127), indicating that heat treatment did not interfere with the determination of bovine $\beta-\mathrm{CN}$ in the assay. The selection of target antigen is crucial in adulteration testing. Hurley et al. (2004a) successfully used a monoclonal antibody specific 

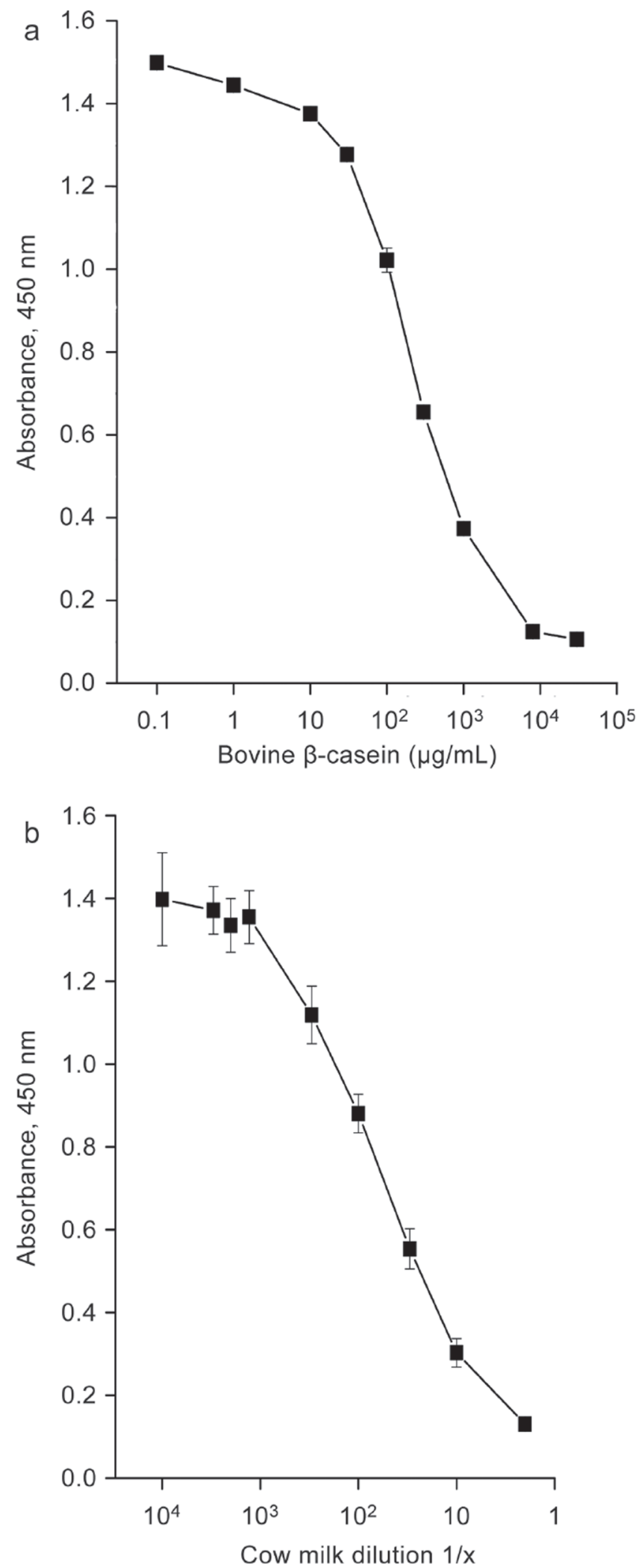

Figure 2. Standard curves of monoclonal antibody 1-9B for detecting bovine $\beta-\mathrm{CN}$ (a) and cow milk (b) by indirect competitive ELISA under optimum conditions. Data points represent mean \pm standard deviation $(\mathrm{n}=3)$.

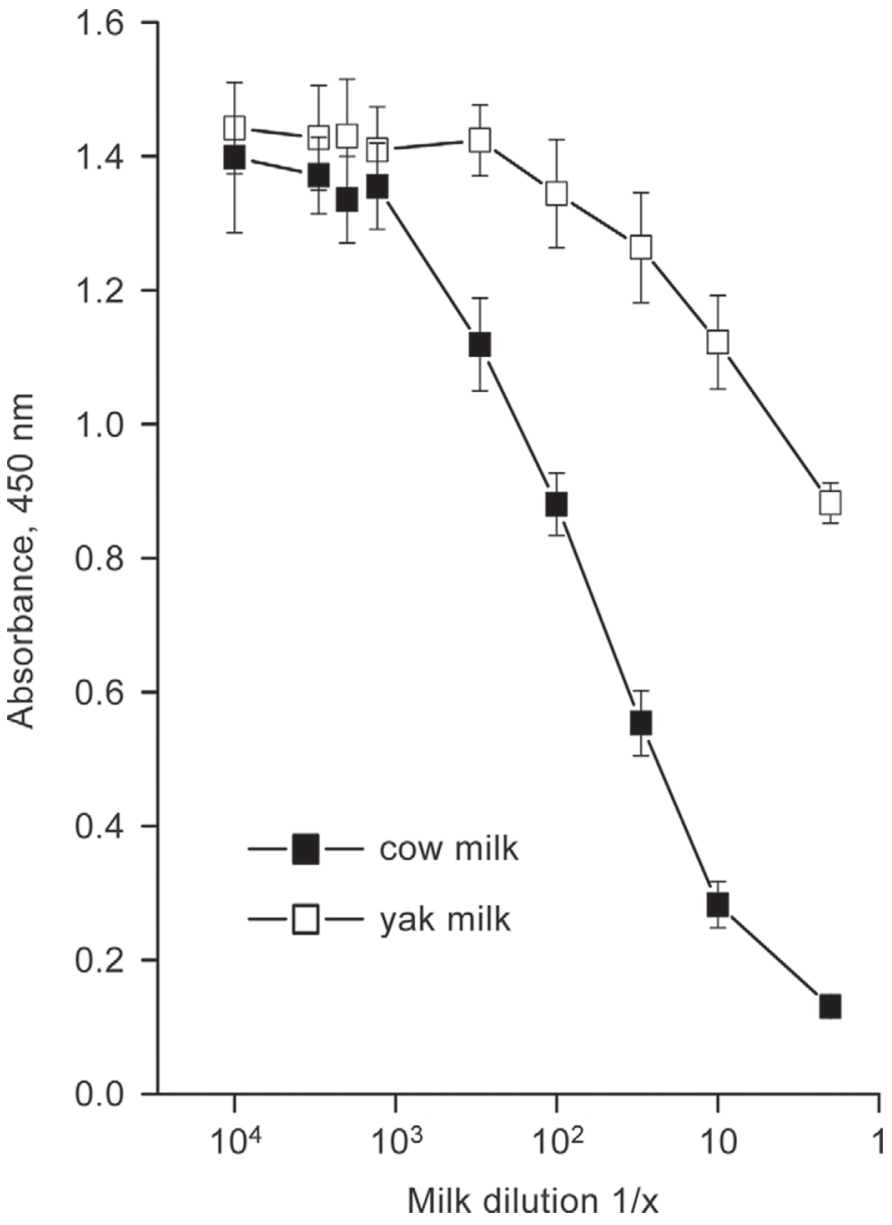

Figure 3. Cross-reactivity of monoclonal antibody 1-9B with yak milk by indirect competitive ELISA under optimum conditions. Cow milk was used as a reference. Data points represent mean \pm standard deviation $(\mathrm{n}=3)$.

against bovine $\operatorname{IgG}$ to detect the presence of fresh and pasteurized cow milk. However, their assay could not be used to detect the presence of UHT or spray-dried cow milk, indicating that whey proteins are sensitive to heat, and severe heat treatment can cause denaturation of the whey protein. Casein has higher heat stability than whey. Our results revealed that the antigenic determinant of bovine $\beta$-CN was not affected by the different heat treatments. Therefore, the antibody against bovine $\beta-\mathrm{CN}$ is suitable for detecting cow milk that has undergone different heat treatments.

Because heat treatment did not affect the detection of cow milk in this study, the assay was then used to detect the presence of cow milk in adulterated yak milk (1-100\%) subjected to different heat treatments. The assay generated similar inhibition curves for the different heat treatments with a working range of 1 to $80 \%$ (Supplementary Figure S1; http://dx.doi.org/10.3168/ jds.2014-8127). Thus, our assay can be used to detect 


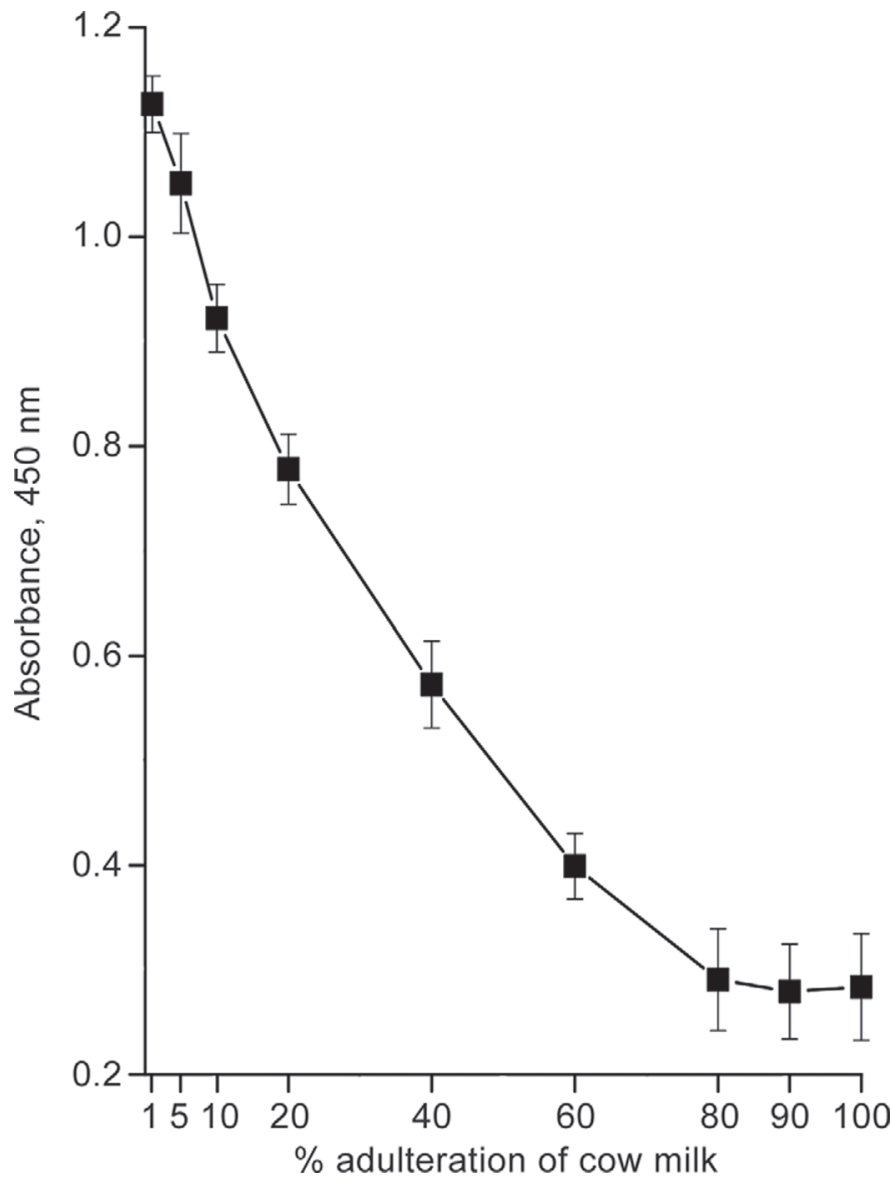

Figure 4. Standard curves of indirect competitive ELISA for the detection of cow milk in yak milk under optimum conditions. Data points represent mean \pm standard deviation $(\mathrm{n}=3)$.

heat-treated adulterated samples. Both UHT-treated yak milk and yak milk powder have a long shelf life and thus are more popular than fresh yak milk in local markets. Therefore, our assay is adequate for the detection of adulterants in these products and will help in the detection of adulterated yak milk.

Acidification Treatment. To assess whether our ELISA could be used in yogurt and other acidulated dairy products, milk samples acidified to $\mathrm{pH} 6.3,5.8$, 5.0 , and 4.6 were analyzed. The inhibition curves of acidified samples were similar to those of fresh (untreated) samples (Supplementary Figure S1; http://dx.doi. org/10.3168/jds.2014-8127). During acidification, as colloidal calcium phosphate is released from the casein micelles, $\beta$-CN dissociates and aggregates with further acidification (Lucey, 2002; Dalgleish and Corredig, 2012). Our results imply that this process did not denature the target epitope. Therefore, acidification did not affect the linear range of ELISA. Our developed method could be applied to detect the adulteration of yak milk yogurt with cow milk.
Rennet Treatment. To assess whether our developed method could be used in cheese, ELISA was used in rennet-treated adulterated milk samples (ranging from 1 to $100 \%$ ). We found no significant differences between the standard curves of raw and rennet-treated milk samples (Supplementary Figure S1; http://dx.doi. org/10.3168/jds.2014-8127). Today, yak cheese has an increasing number of market prospects (Or-Rashid et al., 2008). Combined with the results obtained from the acidified samples, this assay could be used to detect the adulteration of yak cheese.

\section{CONCLUSIONS}

We developed an optimized indirect competitive ELISA to detect the adulteration of yak milk with cow milk using a monoclonal antibody specific for bovine $\beta-\mathrm{CN}$ (mAb 1-9B). The minimum detection limit of this assay was $10 \mu \mathrm{g} / \mathrm{mL}$ of bovine $\beta-\mathrm{CN}$ and the linear range for detecting adulteration was 1 to $80 \%$, which is sufficiently broad for routine adulteration testing. The ELISA method was not affected by heat, acid, or rennet treatment of milk; therefore, the assay could be applied to detecting adulteration with cow milk in different yak dairy products.

\section{ACKNOWLEDGMENTS}

This study was financial supported by International Science \& Technology Cooperation Program of China (Beijing, China; 2011DFA32550) and National Science and Technology Support Program (Beijing, China; 2012BAD28B07 and 2011AA100903).

\section{REFERENCES}

Anguita, G., R. Martín, T. García, P. Morales, A. I. Haza, I. González, B. Sanz, and P. E. Hernández. 1995. Indirect ELISA for detection of cows' milk in ewes' and goats' milks using a monoclonal antibody against bovine $\beta$-casein. J. Dairy Res. 62:655-659.

Anguita, G., R. Martín, T. García, P. Morales, A. I. Haza, I. Gonzalez, B. Sanz, and P. E. Hernandez. 1996. Immunological characterization of bovine casein fractionated by fast protein liquid chromatography (FPLC). Milchwissenschaft 51:21-25.

Bai, W. L., R. H. Yin, Q. L. Dou, W. Q. Jiang, S. J. Zhao, Z. J. Ma, G. B. Luo, and Z. H. Zhao. 2011. Molecular characterization and phylogenetic analysis of a yak (Bos grunniens) $\kappa$-casein cDNA from lactating mammary gland. Mol. Biol. Rep. 38:2711-2718.

Braga, A. L. M., M. Menossi, and R. L. Cunha. 2006. The effect of the glucono- $\delta$-lactone/caseinate ratio on sodium caseinate gelation. Int. Dairy J. 16:389-398.

Brescia, M. A., V. Mazzilli, A. Sgaramella, S. Ghelli, F. P. Fanizzi, and A. Sacco. 2004. ${ }^{1}$ H-NMR characterization of milk lipids: A comparison between cow and buffalo milk. J. Am. Oil Chem. Soc. 81:431-436.

Chen, R. K., L. W. Chang, Y. Y. Chung, M. H. Lee, and Y. C. Ling. 2004. Quantification of cow milk adulteration in goat milk using high-performance liquid chromatography with electrospray ionization mass spectrometry. Rapid Commun. Mass Spectrom. 18:1167-1171. 
Chianese, L., P. Laezza, L. Smaldone, C. Stingo, L. Del Giovine, and F. Addeo. 1990. Evaluation of bovine milk in the buffalo mozzarella cheese by two-dimensional electrophoresis. Sci. Tecn. Latt. Cas. 41:315-326.

Cho, Y. J., D. H. Lee, D. O. Kim, W. K. Min, K. T. Bong, G. G. Lee, and J. H. Seo. 2005. Production of a monoclonal antibody against ochratoxin A and its application to immunochromatographic assay. J. Agric. Food Chem. 53:8447-8451.

Dalgleish, D. G., and M. Corredig. 2012. The structure of the casein micelle of milk and its changes during processing. Annu. Rev. Food Sci. Technol. 3:449-467.

De Marchi, M., V. Bonfatti, A. Cecchinato, G. Di Martino, and P. Carnier. 2010. Prediction of protein composition of individual cow milk using mid-infrared spectroscopy. Ital. J. Anim. Sci. 8:399401

Devi, K. T., M. Mayo, K. Reddy, P. Delfosse, G. Reddy, S. Reddy, and D. Reddy. 1999. Production and characterization of monoclonal antibodies for aflatoxin B1. Lett. Appl. Microbiol. 29:284-288.

EuropeanCommission. 2001. EC 213/2001 Methods for the analysis and quality evaluation of milk and milk products. Off. J. Eur. Comm. 44:L37/31-L37/99.

FASS. 2010. Guidelines for the Care and Use of Agricultural Animals in Research and Teaching. 3rd ed. Federation of Animal Science Societies (FASS), Champaign, IL

García, T., R. Martín, E. Rodríguez, P. Morales, P. E. Hernández, and B. Sanz. 1990. Detection of bovine milk in ovine milk by an indirect enzyme-linked immunosorbent assay. J. Dairy Sci. 73:1489-1493.

Giovannacci, I., C. Guizard, M. Carlier, V. Duval, J. L. Martin, and C. Demeulemester. 2004. Species identification of meat products by ELISA. Int. J. Food Sci. Technol. 39:863-867.

Haza, A. I., P. Morales, R. Martin, T. Garcia, G. Anguita, I. Gonzalez, B. Sanz, and P. E. Hernandez. 1997. Use of a monoclonal antibody and two enzyme-linked immunosorbent assay formats for detection and quantification of the substitution of caprine milk for ovine milk. J. Food Prot. 60:973-977.

Haza, A. I., P. Morales, R. Martin, T. Garcia, G. Anguita, B. Sanz, and P. E. Hernandez. 1999. Detection and quantification of goat's cheese in ewe's cheese using a monoclonal antibody and two ELISA formats. J. Sci. Food Agric. 79:1043-1047.

Hurley, I. P., R. C. Coleman, H. E. Ireland, and J. H. H. Williams. 2004a. Measurement of bovine IgG by indirect competitive ELISA as a means of detecting milk adulteration. J. Dairy Sci. 87:543549 .

Hurley, I. P., R. C. Coleman, H. E. Ireland, and J. H. H. Williams. 2006. Use of sandwich IgG ELISA for the detection and quantification of adulteration of milk and soft cheese. Int. Dairy J. 16:805-812.

Hurley, I. P., H. Elyse Ireland, R. C. Coleman, and J. H. H. Williams. 2004b. Application of immunological methods for the detection of species adulteration in dairy products. Int. J. Food Sci. Technol. 39:873-878.
Köhler, G., and C. Milstein. 1975. Continuous cultures of fused cells secreting antibody of predefined specificity. Nature 256:495-497.

Lee, C. C., H. S. Chang, and H. S. Sheen. 2004. A quick novel method to detect the adulteration of cow milk in goat milk. Asian-australas. J. Anim. Sci. 17:420-422.

Li, H., Y. Ma, Q. Li, J. Wang, J. Cheng, J. Xue, and J. Shi. 2011. The chemical composition and nitrogen distribution of Chinese yak (Maiwa) milk. Int. J. Mol. Sci. 12:4885-4895.

Livingstone, K. M., J. A. Lovegrove, and D. I. Givens. 2012. The impact of substituting SFA in dairy products with MUFA or PUFA on CVD risk: Evidence from human intervention studies. Nutr. Res. Rev. 25:193-206.

Lucey, J. A. 2002. Formation and physical properties of milk protein gels. J. Dairy Sci. 85:281-294

Moatsou, G., and E. Anifantakis. 2003. Recent developments in antibody-based analytical methods for the differentiation of milk from different species. Int. J. Dairy Technol. 56:133-138.

Nicolaou, N., Y. Xu, and R. Goodacre. 2010. Fourier transform infrared spectroscopy and multivariate analysis for the detection and quantification of different milk species. J. Dairy Sci. 93:56515660.

Nikkhah, A. 2011. Science of camel and yak milks: Human nutrition and health perspectives. Food Nutr. Sci. 2:667-673.

Or-Rashid, M. M., N. E. Odongo, B. Subedi, P. Karki, and B. W. McBride. 2008. Fatty acid composition of yak (Bos grunniens) cheese including conjugated linoleic acid and trans-18:1 fatty acids. J. Agric. Food Chem. 56:1654-1660.

Rodríguez, E., R. Martín, T. García, J. I. Azcona, B. Sanz, and P. E. Hernandez. 1991. Indirect ELISA for detection of goats' milk in ewes' milk and cheese. Int. J. Food Sci. Technol. 26:457-465.

Rodriguez-Otero, J. L., M. Hermida, and J. Centeno. 1997. Analysis of dairy products by near-infrared spectroscopy: A review. J. Agric. Food Chem. 45:2815-2819.

Sheng, Q., J. Li, M. S. Alam, X. Fang, and M. Guo. 2008. Gross composition and nutrient profiles of Chinese yak (Maiwa) milk. Int. J Food Sci. Technol. 43:568-572.

Song, H., H. Xue, and Y. Han. 2011. Detection of cow's milk in Shaanxi goat's milk with an ELISA assay. Food Contr. 22:883-887.

Walker, J. M. 1996. The Protein Protocols Handbook. Humana Press Inc., Totowa, NJ.

Wiener, G., J. L. Han, and R. J. Long. 2003. The Yak. 2nd ed. FAO Regional Office for Asia and the Pacific, Bangkok, Thailand

Yin, W., J. Liu, T. Zhang, W. Li, W. Liu, M. Meng, F. He, Y. Wan, C. Feng, and S. Wang. 2010. Preparation of monoclonal antibody for melamine and development of an indirect competitive ELISA for melamine detection in raw milk, milk powder, and animal feeds. J. Agric. Food Chem. 58:8152-8157.

Zi, X. D., H. Lu, R. H. Yin, and S. W. Chen. 2008. Development of embryos after in vitro fertilization of bovine oocytes with sperm from either yaks (Bos grunniens) or cattle (Bos taurus). Anim. Reprod. Sci. 108:208-215. 